\title{
Interstitial granulomatous dermatitis: rare cutaneous manifestation of rheumatoid arthritis*
}

\author{
Isis Suga Veronez ${ }^{1}$ \\ Neusa Yuriko Valente ${ }^{1}$ \\ Thaís Helena Yasuda ${ }^{1}$
}

\author{
Fernando Luiz Dantas ${ }^{1}$ \\ Priscila Kakizaki ${ }^{1}$ \\ Thaís do Amaral Cunha ${ }^{1}$
}

DOI: http:/ / dx.doi.org/10.1590/abd1806-4841.20153263

\begin{abstract}
A bstract: Besides being an uncommon clinicopathological entity, interstitial granulomatous dermatitis, also described as interstitial granulomatous dermatitis with arthritis (IGDA), has shown a wide spectrum of clinical manifestations, such as linear and erythematous lesions, papules, plaques and nodules. Histological features include dense dermal histiocytic infiltrate, usually in a palisade configuration, and scattered neutrophils and eosinophils. We describe a middle aged woman with rheumatoid arthritis of difficult management and cutaneous lesions compatible with IGDA.
\end{abstract}

Keywords: Rheumatoid arthritis; Dermatitis; Granuloma

\section{INTRODUCTION}

Interstitial granulomatous dermatitis was initially described by Ackerman et al in 1993. ${ }^{1}$ It is an infrequent dermatosis, more common in women with a previous diagnosis of rheumatoid arthritis (RA). ${ }^{2}$

Its clinical manifestations are variable. Classically it presents itself as linear subcutaneous cords, known as rope sign. ${ }^{1}$ Other clinical forms were reported such as papules, subcutaneous plaques, annular lesions or nodules, predominantly in lateral walls of thorax, abdomen and medial surface of thighs. ${ }^{2-4}$ Lesions are usually asymptomatic. ${ }^{5}$

At the histopathological examination, infiltration of reticular dermis was observed with predominance of interstitial and palisaded histiocytes and some areas of collagenous degeneration, associated with a lower number of neutrophils and eosinophils. ${ }^{6}$

The main associated disease is RA, which may be diagnosed before, concomitantly or after the onset of lesions. ${ }^{5}$ There are reports of association with several diseases, besides medication, especially antihypertensive drugs. ${ }^{2-6}$ In these cases, a more peculiar histopathological picture was observed, with vacuolar interface dermatitis. ${ }^{3}$

\section{CASE REPORT}

Female patient, 52 years old, came to the dermatological ambulatory with a two-month history of plaques and grouped nodules, erythematous-purplish, some infiltrates with annular configuration and symmetric distribution on medial surface of thighs, associated with erythematous papules on the left elbow with local pruritus (Figures 1 and 2).

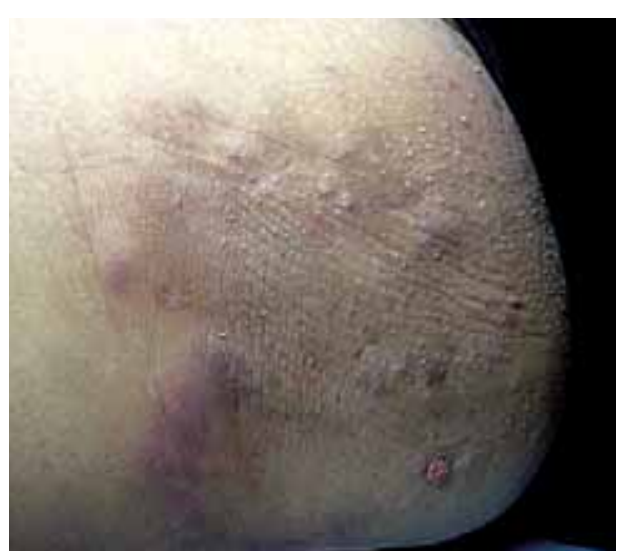

FIGURE 1:

Right thigh. Papules, a n $\mathrm{n} \mathrm{ul}$ a r plaques and erythematous-purplish infiltrated nodules on medial surface of right thigh 


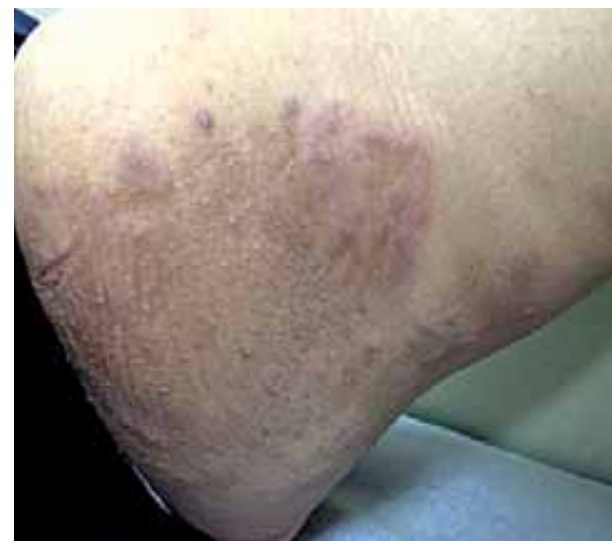

Figure 2:

Left thigh. Papules, a n $\mathrm{nu} l$ a r plaques and erythematous-purplish infiltrated nodules on medial surface of left thigh

Pathological history: RA, diagnosed 10 years ago with symmetrical deforming polyarthritis of the small-joints of hands and being monitored by the Rheumatology Service of HSPE-SP; systemic arterial hypertension and obesity. She was using: prednisone $5 \mathrm{mg} /$ day, methotrexate $7.5 \mathrm{mg} /$ week, losartan 50 $\mathrm{mg} /$ day, fluoxetine $20 \mathrm{mg} /$ day, acetaminophen and naproxen sporadically, in case of joint pain.

Laboratory tests: rheumatoid factor present at high titers on the occasion of rheumatoid arthritis diagnosis, anti-cyclic citrullinated peptide antibodies present, increased inflammatory markers, without alterations in other tests.

The patient was submitted to incisional biopsy of skin and the histopathological study revealed interstitial granulomatous dermatitis, without evidence of vacuolar interface dermatitis on both thighs and elbow lesions (Figures 3 to 6).

\section{DISCUSSION}

IGDA is a rare dermatosis, initially described by Ackerman et al as Ackerman syndrome, in $1993 .{ }^{1}$

Although the original manifestation had been described as subcutaneous linear nodules, also known as rope sign ${ }^{1}$, later reports showed a clinical spectrum

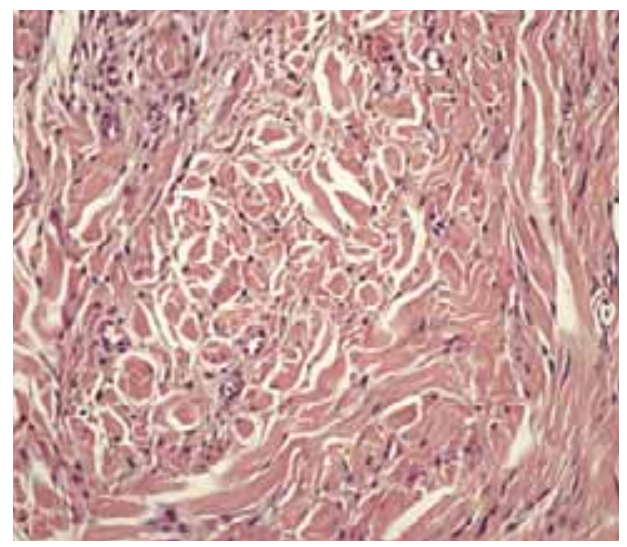

FIGURE 3: Elbow lesion. Detail of interstitial granulomatous infiltrate amid thickened collagen. $\mathrm{HE}$ AO 200x

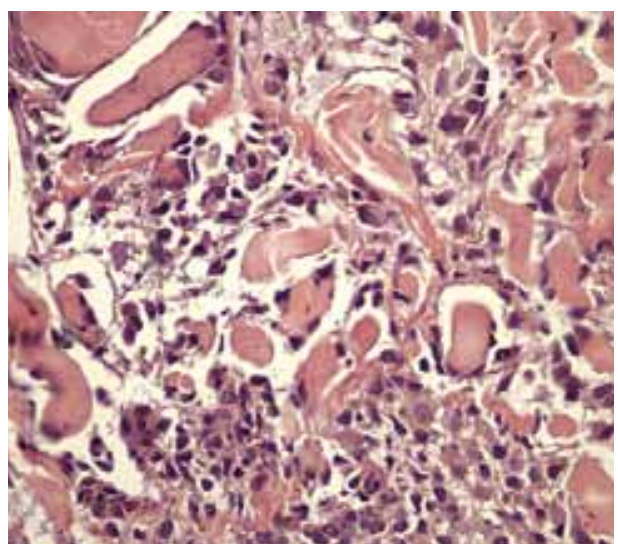

FIGURE 4: Thigh lesion. Detail of infiltrate with histiocytes, lymphocytes, eosinophils and neutrophils amid thickened collagen. HE AO 400x

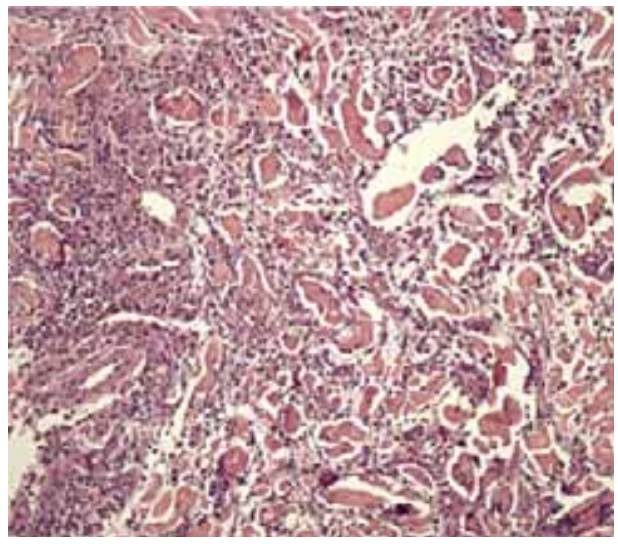

Figure 5: Thigh lesion. Dense inflammatory infiltrate in interstitial thickened collagen. $\mathrm{HE}$ $\mathrm{AO}$ $200 x$

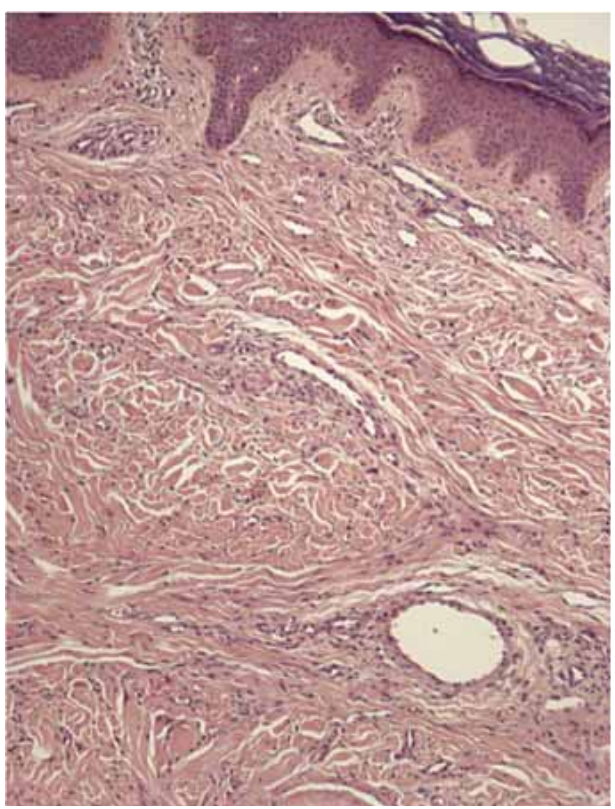

FIGURE 6: Elbow lesion. Normal epidermis for this site, without basal cell vacuolar degeneration. Dermis with moderate infiltrate predominantly histiocytic amid deteriorated and thickened collagen. HE AO 100x

quite heterogeneous which vary from hyperpigmented, erythematous papules, subcutaneous plaques, annular lesions to firm red-purplish nodules as observed in our patient. ${ }^{2-4}$ The lesions are usually asymptomatic, but can be slightly pruritic or painful. ${ }^{5}$ 
The histopathological examination defines the diagnosis characterized as dense and diffuse interstitial infiltrate in the reticular dermis, composed of histiocytes in a palisade arrangement, sometimes with necrobiosis of collagen and involved by some neutrophils and eosinophils. ${ }^{6}$ Usually there are deposits of mucin and absence of vasculitis. ${ }^{2,7}$ This last characteristic is useful in distinguishing it from another uncommon disease and has been reported several times in patients with RA, the palisaded neutrophilic granulomatous dermatitis. It is histopathologically characterized for affecting all the dermis, differently from IGDA, which is located in the middle and deep dermis and demonstrates an infiltrate rich in neutrophils, with vascular alterations and leukocytoclasia.

Its physiopathology is uncertain, however the association with autoimmune diseases and vasculitides suggests a mechanism mediated by immunocomplexes. ${ }^{5,6}$ Interstitial granulomatous dermatitis is more commonly described in women with a previous diagnosis of RA, such as the present case. ${ }^{2,5}$ Other associated diseases already reported in the literature include systemic lupus erythematosus, antiphospholipid syndrome, autoimmune thyroiditis and autoimmune hepatitis, Churg-Strauss syndrome, Behcet's disease, pulmonary paracoccidioidomycosis, pulmonary silicosis, chronic uveitis, promyelocytic leukemia and even bronchial and esophageal squamous cell carcinomas such as paraneoplastic syndrome..$^{2-6}$

Pharmacological etiology has also been reported and the most frequently drugs involved are the antihypertensives, such as the angiotensin-converting-enzyme inhibitors, calcium channel blockers, beta blockers, diuretics, in addition to hypolipidemic agents, anticonvulsants, antihistamines and TNF-alpha blockers. ${ }^{3,4,6,7}$ In these cases, the histopathological examination is commonly differentiated with vacuolar degenerative changes, exocytosis of lymphocytes and absence of neutrophils. ${ }^{3}$ The absence of vacuolar interface dermatitis and the fact that the patient had suspended all medication for six months based on her own decision, with persistent IGDA lesions, speak against this cause.

Differential diagnosis includes other entities related to rheumatoid arthritis, such as rheumatoid nodules, rheumatoid vasculitis, palisaded neutrophilic and granulomatous dermatitis, in addition to rheumatoid neutrophilic dermatosis, which, unlike the latter, presents neutrophilic dermal infiltrate and leukocytoclasia without vasculitis under histopathology. ${ }^{8}$ Lichen planus, erythema multiforme, erythema elevatum diutinum ${ }^{4}$ and granuloma annulare must also be considered, for it is considered a variant of the latter. ${ }^{9}$

The therapy of choice is still not well-defined..$^{2-3,5-7}$ Different treatments have been reported in literature with different degrees of success, ranging from topical or systemic corticosteroids, anti-inflammatories, methotrexate, hydroxychloroquine, amid others. $^{3-7}$ A spontaneous resolution my also occur in weeks to months, with surges and relapses..$^{3,5-6}$

Considering IGDA as a rare entity, the knowledge of its manifestations and its essential association with rheumatoid arthritis contributes to clinical suspicion, since its wide spectrum presentation makes its diagnosis difficult. Dermatologists should be alert to this diagnostic possibility, for they are already in a privileged position when monitoring these patients. $]$

\section{REFERENCE}

1. Ackerman A. Clues to Diagnosis in Dermatopathology. Chicago IL: ASCP Press;1993. p. 309-12.

2. Marmon S, Robinson M, Meehan SA, Franks AG Jr. Lupus-erythematous associated interstitial granulomatous dermatitis. Dermatol Online J. 2012;18:31.

3. Jabbari A, Cheung W, Kamino H, Soter NA. Interstitial granulomatous dermatitis with arthritis. Dermatol Online J. 2009;15:22.

4. Sayah A, English JC. Rheumatoid arthritis: A review of the cutaneous manifestations. J Am Acad Dermatol. 2005;53:191-209.

5. Antunes J, Pacheco D, Travassos AR, Soares-Almeida LM, Filipe P, SacramentoMarques M. Autoimmune thyroiditis presenting as interstitial granulomatous dermatitis. An Bras Dermatol. 2012;87:748-51.

6. Serra S, Monteiro P, Pires E, Vieira R, Telechea O, Inês L, et al. Relapsing polychondritis, interstitial granulomatous dermatitis and antiphospholipid syndrome: an unusual clinical association. Acta Reumatol Port. 2011;36:292-7.

7. Felcht M, Faulhaber J, Göttmann U, Koenen W, Goerdt S, Goebeler M. Interstitial granulomatous dermatitis (Ackerman's Syndrome). Eur J Dermatol. 2010;20:661-2.

8. Mashek HA, Pham CT, Helm TN, Klaus M. Rheumatoid Neutrophilic Dermatitis. Arch Dermatol. 1997;133:757-60.

9. Romiti R, Sakai N. Dermatite intersticial granulomatosa com artrite. Variante do granuloma anular? An Bras Dermatol. 1999;74149-52.

\begin{tabular}{l}
\hline \hline M AILING ADDRESS: \\
Fernando Luiz Teixeira Dantas \\
Rua Borges Lagoa, 1755, $4^{\circ}$ andar - V ila Clementino \\
04038-034 - São Paulo - SP \\
Brazil \\
E-mail: fernandotdantas@uol.com.br
\end{tabular}

M AILING ADDRESS:

Fernando Luiz Teixeira D antas

Rua Borges Lagoa, 1755, $4^{\circ}$ andar - Vila Clementino

Brazil

E-mail: fernandotdantas@uol.com.br

How to cite this article: Veronez IS, Dantas FL, Valente NY, Kakizaki P, Yasuda TH, Cunha TA. Interstitial granulomatous dermatitis: rare cutaneous manifestation of rheumatoid arthritis. An Bras Dermatol. 2015; 90(3):391-3. 